\title{
СОВРЕМЕННЫЙ ВЗГЛЯД НА НАЗНАЧЕНИЕ, СТРУКТУРУ И АНАЛИЗ ОТЧЕТА О ФИНАНСОВЫХ РЕЗУЛЬТАТАХ
}

\author{
(C) 2020 Юрченко Кристина Алексеевна \\ Отдел аудиторских услуг, специалист \\ ООО «Эрнст энд Янг», Россия, Москва \\ E-mail: gabikris@mail.ru
}

(C) 2020 Петров Александр Михайлович

доктор экономических наук, профессор Департамента учета, анализа и аудита Финансовый университет при Правительстве Российской Федерации, Россия, Москва

E-mail:palmi@inbox.ru

В статье рассмотрено современное состояние структуры отчета о финансовых результатах, приведены принципы его построения, рассмотрено влияние Международных стандартов финансовой отчетности, а в частности структуры PnL на российский отчет о финансовых результатов, определены методики проведения его внешнего анализа, а именно: структурно-динамического анализа доходов и расходов, их соотношения и оценки, динамического анализа показателей прибыли, структурного анализа бухгалтерской прибыли и оценка изменений в структуре прибыли, факторного анализа показателей прибыли и оценки степени их влияния, коэффициентного анализа, а также рассмотрены основные принципы внутреннего анализа отчет о финансовых результатах.

Ключевые слова: финансовая отчетность, управленческая отчетность, международные стандарты финансовой отчетности, принципы, доходы и расходы, внешний и внутренний анализ.

Широко известно, что определение финансового результата и начисление налога на прибыль организаций являются одним из самых важных аспектов учета предприятий в процессе их деятельности.

Отчет о финансовых результатах в составе финансовой отчетности занимает особое место. Важнейшая цель формирования и составления отчета о финансовых результатах - это обеспечение информацией лиц, заинтересованных в результатах деятельности организации. Отчет о финансовых результатах содержит информацию, которая позволяет:

- оценить динамику изменения доходов и расходов отчетного периода с периодом, предшествующим предыдущему;

- провести анализ состава, структуры и динамики показателей прибыли (валовой, прибыли от продаж, бухгалтерской прибыли);

- провести факторный анализ формирования финансовых результатов и оценить динамику рентабельности продаж;

- рассчитать коэффициенты рентабельности, провести их анализ и другие возможности.

Также, информация, содержащаяся в отчете о финансовых результатах может быть полезна для:
- определения эффективности принятия управленческих решений и их обоснования, а также для анализа результатов хозяйственной деятельности организации;

- исчисления дивидендов и их последующего распределения между участниками общества (учредителями или акционерами);

- составления прогноза хозяйственной деятельности организации на перспективу.

Собственники организации, инвесторы или кредиторы по данным отчета о финансовых результатах могут определять различные показатели доходности путем сопоставления различных показателей финансовых результатов с инвестированными средствами в организацию, раскладывая эти показатели по факторам. Например, определить фактическую доходность от вложений возможно путем сопоставления активов организации с фактически полученной прибылью.

Отчет о финансовых результатах является официальным документом, характеризующим эффективность и успешность хозяйственной деятельности организации за определенный период времени. Отчет о финансовых результатах в бизнес среде используется для определения различных видов рентабельности, инвестици- 
онной привлекательности, а также кредитоспособности организации. С помощью отчета о финансовых результатах собственники, инвесторы и кредиторы могут прогнозировать объемы денежных потоков.

В основу построения отчета о финансовых результатах положено пять принципов, разработанных на законодательном уровне с тем, чтобы отчет о финансовых результатах и пояснительная записка к бухгалтерской отчетности несли в себе информацию, на основании которой можно определить фактическую доходность организации, и именно их мы рассмотрим в таблице 1.

В структуру отчета о финансовых результатах входят следующие данные:

- об общих доходах организации за отчетный период;

- о затратах, связанных с получением доходов;

- обо всех периодических доходах и расходах, которые не связаны с конкретными видами деятельности организации.

Все преобразования отчета о финансовых результатах в настоящее время проходят под влиянием Международных стандартов финансовой отчетности и вызваны сближением российской системы бухгалтерского учета и международных стандартов финансовой отчетности. Следствием этого является существенное сближение содержания российского отчета о финансовых результатах содержанию отчету о совокупном доходе по МСФО.

Первостепенной целью составления финансовой отчетности по правилам международных стандартов финансовой отчетности является расширение круга пользователей отчетности, то есть пользователями отчетности в таком случае являются не только российские пользователи финансовой отчетности, но и зарубежные.

Согласно МСФО (IAS) 1 «Представление финансовой отчетности», отчет о совокупном доходе (PnL) или отчет о финансовых результатах должен включать как минимум следующие статьи:

- выручка;

- затраты по финансированию;

- доля прибыли и убытков ассоциированных компаний и совместной деятельности, исчисляемая методом участия;

- расходы по налогу;

- прибыль или убыток;

- общий совокупный доход за период.

Несмотря на схожесть форм отчетности, методология формирования показателей отчета о финансовых результатах и отчета о совокупном доходе по МСФО различается. Например, согласно МСФО 18 «Выручка» показатель выручки в отчете о совокупном доходе признается и отражается, если у организации имеется высокая вероятность получения экономических выгод и величина экономических выгод может быть с точностью определена и идентифицирована. Согласно российскому ПБУ 9/99 «Доходы организации», помимо критериев признания выручки, как приведены в МСФО, дополнительно присутствует критерий признания выручки, такой как переход права собственности. Если это условие (критерий) не соблюдается, то по РСБУ выручка не признается и не отражается в отчете о финансовых результатах.

Содержание отчета о финансовых результатах и его показатели позволяют проводить факторный анализ прибыли или убытка, а также выделять факторы, оказывающие на финансовый

Таблица 1. Принципы построения отчета о финансовых результатах

\begin{tabular}{|l|l|}
\hline \multicolumn{1}{|c|}{ Наименование принципа } & \multicolumn{1}{|c|}{ Экономическое содержание } \\
\hline $\begin{array}{l}\text { Принцип исчисления финансового результата } \\
\text { методом брутто }\end{array}$ & $\begin{array}{l}\text { Недопущение взаимозачета статей доходов и расхо- } \\
\text { дов (исключение свернутого представления статей) }\end{array}$ \\
\hline Принцип разделения & $\begin{array}{l}\text { Разделение доходов и расходов по их экономическо- } \\
\text { му содержанию (по видам) }\end{array}$ \\
\hline $\begin{array}{l}\text { Принцип построения отчета о финансовых } \\
\text { результатах по области возникновения }\end{array}$ & $\begin{array}{l}\text { Отражение расходов в отчетности по их функци- } \\
\text { ональному назначению (в областях производства, } \\
\text { управления и сбыта) }\end{array}$ \\
\hline Принцип периодизации & $\begin{array}{l}\text { Принятие к учету и отражение доходов и расходов в } \\
\text { том отчетном периоде, в котором они были действи- } \\
\text { тельно осуществлены }\end{array}$ \\
\hline Принцип разделения результата & $\begin{array}{l}\text { Раздельный расчет и отражение в отчетности фи- } \\
\text { нансового результата от основной и прочей видов } \\
\text { деятельности }\end{array}$ \\
\hline
\end{tabular}


результат влияние, и проводить их оценку.

Методология анализа отчета о финансовых результатах, последовательность и набор этапов анализа зависят от того, проводится анализ финансовой отчетности внешними пользователями или внутренними пользователями с дополнительным анализом данных управленческого учета. Отсюда, можно провести границу и выделить внутреннюю и внешнюю методики анализа отчета о финансовых результатах. Методика проведения внешнего анализа отчета о финансовых результатах может включать в себя следующие этапы анализа:

- структурно-динамический анализ доходов и расходов организации за определенный период, их соотношение и оценка;

- динамический анализ показателей прибыли (горизонтальный анализ);

- структурный анализ бухгалтерской прибыли и оценка изменений в структуру прибыли (горизонтальный анализ прибыли до налогообложения);

- факторный анализ показателей прибыли и оценка степени их влияния;

- коэффициентный анализ.

Первоначальным этапом любого анализа отчета о финансовых результатах является структурно-динамический анализ доходов и расходов организации, так как любой показатель прибыли исчисляется как разница между доходами и расходами. Задачами структурно-динамического анализа доходов и расходов является изучение их структуры и уровня в предыдущем и отчетном периодах. Оценка и выяснение причин структурной динамики доходов и расходов организации в отчетном периоде, по сравнению с периодом, предшествующему отчетному. Вместе с тем определяется качество доходов. Чем большие удельный вес в структуре доходов организации занимают доходы от обычных видов деятельности, тем более высокое качество доходов наблюдается. Для более детального анализа расходов организации используют пояснения к бухгалтерскому балансу и отчету о финансовых результатах. С помощью пояснений к бухгалтерскому балансу и отчету о финансовых результатах проводят анализ расходов по элементам и по функциям. Структурно-динамический анализ доходов и расходов дополняется относительными показателями, характеризующими отношение общей суммы доходов к общей сумме расходов и др.
Второй этап анализа отчета о финансовых результатах включает в себя горизонтальный анализ показателей прибыли, предусматривающий оценку уровня и динамики показателей прибыли, а также выявления влияния отдельных доходов и расходов на показатели прибыли организации. Далее производится оценка стабильности доходов и прогнозирование их получения в будущем периоде.

Следующим шагом анализа отчета о финансовых результатах является вертикальный анализ отчета о финансовых результатах, который включает в себя оценку влияния отдельных статей доходов и расходов на показатели прибыли организации. При проведении вертикального анализа отчета о финансовых результатах могут применяться различные методологические подходы анализа структуры формирования конечного финансового результата. Многие статьи доходов и расходов отчета о финансовых результатах не оказывают прямого воздействия на выручку от продаж, что затрудняет анализ и является основным недостатком такого подхода. Оптимальным подходом вертикального анализа является анализ структуры бухгалтерской прибыли или прибыли до налогообложения. При анализе структуры бухгалтерской прибыли изучается изменения в ее составе динамики маржинальной прибыли, финансового результата от прочих доходов и расходов и чистой прибыли. О положительных тенденциях свидетельствует увеличение в динамике доли маржинальной и чистой прибыли.

Факторный анализ показателей прибыли отчета о финансовых результатах является сложнейшим этапом анализа, так как на финансовый результат может оказывать влияние огромное количество неоднородных факторов. Некоторые факторы довольно просто определить приемами факторного анализа, так как они оказывают прямое непосредственное влияние на показатели финансового результата. Другие факторы определить довольно затруднительно или вообще невозможно, так как они оказывают слабое косвенное влияние на показатели финансовых результатов организации. Существуют внешние и внутренние факторы, оказывающие влияние на финансовый результат. К внешним факторам относятся: инфляционное или государственное влияние на цены, нарушение поставщиками, финансовыми и банковскими органами дисциплины договоров и другие. Организация не мо- 
жет оказывать влияние на внешние факторы, в то время как на внутренние возможно, так как они зависят от производственно-хозяйственной деятельности самой организации.

Внутренние факторы, оказывающие влияние на финансовый результат, можно классифицировать на факторы первого, второго, третьего порядка и т.д. К факторам первого порядка, можно отнести факторы, оказывающие влияние и формирующие бухгалтерскую прибыль в отчете о финансовых результатах. Приведем аддитивную модель этих факторов по формуле 1:

БП = Пп + ДДО + ПП - ПУ + ПД - ПР,

где БП - бухгалтерская прибыль или прибыль до налогообложения;

Пп - прибыль от продаж;

ДДО - доходы от участия в других организациях;

ПП и ПУ - проценты к получению и уплате соответственно;

ПД и ПР - соответственно прочие доходы и прочие расходы.

Факторы второго порядка оказывают влияние на бухгалтерскую прибыль через влияние на прибыль от продаж. К эти факторам можно отнести выручку от продаж без учета НДС (B), производственную себестоимость (ПСБ), коммерческие и управленческие расходы соответственно (КР и УР).

Факторную модель бухгалтерской прибыли с учетом вышеизложенных факторов представим в виде аддитивной модели в соответствии с формулой 2:

БП = В - ПСБ - КР - УР + ДДО + ПП - ПУ

+ ПД - ПР,

где В - выручка от продаж без учета НДС;

ПСБ - производственная себестоимость;

КР - коммерческие расходы;

УР - управленческие расходы;

Методом цепных подстановок можно установить влияние каждого фактора, включенного в аддитивную факторную модель бухгалтерской прибыли. Немаловажным при проведении факторного анализа является оценка влияния фактора налогообложения путем изучения динамики суммы исчисленного налога на прибыль, влияния налога на прибыль на изменение чистой прибыли, а также оценке применения эффективной ставки налогообложения.

Другой точки зрения придерживался А.Д. Шеремет. Он считал, что измерителем истинной эффективности производствен- но-хозяйственной деятельности организации является рентабельность продаж по чистой бухгалтерской прибыли. При проведении анализа рентабельности продаж производят оценку уровня рентабельности в определенной отрасли хозяйствования, оценивают динамику изменения этого показателя, а также выявляют основные факторы, оказывающие непосредственное влияние на рентабельность продаж. При факторном анализе рентабельности продаж (Рпб), рассчитанной по бухгалтерской прибыли, можно применить аддитивно-кратную факторную модель (формула 3):

$$
\begin{aligned}
& \text { Рпб = (В - ПСБ - КР -УР + ДДО + ПП - ПУ } \\
& + \text { ПД - ПР }): \text { В }
\end{aligned}
$$

Из вышеприведенной факторной модели следует, что на рентабельность продаж по бухгалтерской прибыли оказывает прямое воздействие те же факторы, что и на бухгалтерскую прибыль. Количественное влияние каждого фактора можно измерить способом цепных подстановок. Что касается внутреннего анализа отчета о финансовых результатах, то он должен проводиться, основываясь не только на данных отчета о финансовых результатах, но и на основании данных управленческой отчетности. Внутренний анализ отчета о финансовых результатах помимо вышерассмотренных этапов отчета о финансовых результатах должен обязательно включать анализ качества прибыли, прогноз ее величины в будущем. При внутреннем анализе углубленно анализируются доходы и расходы организации с их детализацией. Анализ доходов должен проводиться в тесной связи в сравнение со среднеотраслевой рентабельностью, анализом рынка, анализа конкурентов и оценке рисков. Анализ расходов производится с учетом их детализации по экономическому содержанию, по статьям калькуляции, по центрам ответственности, по процессам. При анализе расходов снижение соотношения выручки к производственной себестоимости, коммерческим и управленческим расходом свидетельствует о проблемах контроля над расходами.

Планирование и прогнозирование показателей прибыли, оптимизация расходов и увеличение величины финансового результата деятельности организации являются завершающим этапом внутреннего анализа отчета о финансовых результатах.

Подводя итог, можно сделать вывод, что отчет о финансовых результатах является основ- 
ной формой бухгалтерской финансовой отчетности. Именно отчет о финансовых результатах отображает финансовую картину организации на отчетную дату, а также полученные финансовые результаты организацией в отчетном пери- оде. Финансовые результаты представляют собой наиболее информационно значимую часть бухгалтерской отчетности, дополняя данные бухгалтерского баланса.

\section{Библиографический список}

1. Налоговый Кодекс Российской Федерации, часть 1 от 31.07.1998 N146-Ф3 и часть 2 от 05.08.2000 N117-Ф3 (ред. от 27.12.2019) // СПС КонсультантПлюс.

2. Федеральный закон «О бухгалтерском учете» от 06.12.2011 года N402-Ф3 (ред. от 26.07.2019 N247-Ф3) // СПС КонсультантПлюс.

3. Приказ Минфина России от 29.07.1998 N34н «Об утверждении Положения по ведению бухгалтерского учета и бухгалтерской отчетности в Российской Федерации» (ред. от 11.04.2018) // СПС КонсультантПлюс.

4. Приказ Минфина России от 06.05.1999 N32н (ред. от 06.04.2015) «Об утверждении Положения по бухгалтерскому учету «Доходы организации» ПБУ 9/99» // СПС КонсультантПлюс.

5. Приказ Минфина России от 06.05.1999 N33н (ред. от 06.04.2015) «Об утверждении Положения по бухгалтерскому учету «Расходы организации» ПБУ 10/99» (Зарегистрировано в Минюсте России 31.05.1999 N1790) // СПС КонсультантПлюс.

6. Приказ Минфина РФ от 02.07.2010 N66н «О формах бухгалтерской отчетности организации» (ред. от 19.04.2019) // СПС КонсультантПлюс.

7. Агеева О.А. Основы бухгалтерского учета и анализа: учебник / О.А. Агеева, С. С. Серебренников, С.С. Харитонов и др.; под ред. Н. Гринчик.- М.: издательство СПб.: Питер, 2017.- 448 с.

8. Агеева О.А. Бухгалтерский учет и анализ: учебник / О.А. Агеева, Л.С. Шахматова.- М.: издательство Юрайт, 2016. - 509 c.

9. Булгакова С.В. Теория бухгалтерского учета: учебник / С.В. Булгакова, Н.Г. Сапожникова.- М.: Кнорус, 2016. $-188 \mathrm{c}$.

10. Наумова Н.А. Бухгалтерский учет и анализ / Н.А. Наумова, М.В. Беллендир, Е.В. Хоменко - М.: Кнорус, 2018. $-630 \mathrm{c}$ 